\title{
Overlap of quantitative trait loci for early growth rate, and for body weight and age at onset of sexual maturity in chickens
}

\author{
B K Podisi, S A Knott ${ }^{1}$, I C Dunn, A S Law, D W Burt and P M Hocking \\ The Roslin Institute and Royal (Dick) School of Veterinary Studies, University of Edinburgh, Roslin, Midlothian, \\ EH25 9PS, Scotland, UK and ${ }^{1}$ Institute of Evolutionary Biology, University of Edinburgh, King's Buildings, West Mains \\ Road, Edinburgh, EH9 3JT, Scotland, UK
}

Correspondence should be addressed to B K Podisi; Email: baitsi.podisi@roslin.ed.ac.uk

\begin{abstract}
Critical age, weight and body composition have been suggested as necessary correlates of sexual maturity. A genome scan to identify quantitative trait loci (QTL) for age and body weight at first egg (AFE and WFE) was conducted on 912 birds from an $F_{2}$ broiler-layer cross using 106 microsatellite markers. Without a covariate, QTL for body WFE were detected on chromosomes 2, 4, 8, 27 and Z and a single QTL for AFE was detected on chromosome 2. With AFE as a covariate, additional QTL for body WFE were found on chromosomes 1 and 13, with abdominal fat pad as covariate a QTL for body WFE was found on chromosome 1. With body WFE as covariate, additional QTL for AFE were found on chromosomes 1, 3, 4, 13 and 27. The QTL generally acted additively and there was no evidence for epistasis. Consistent with the original line differences, broiler alleles had positive effects on body WFE and negative effects on AFE, whereas the phenotypic correlation between the two traits was positive. The mapped QTL for body WFE cumulatively accounted for almost half the body weight difference between the chicken lines at puberty. Overlapping QTL for body WFE and body weight to 9 weeks of age indicate that most QTL affecting growth rate also affect body WFE. The co-localisation of QTL for body weight, growth and sexual maturity suggests that body weight and growth rate are closely related to the attainment of sexual maturity and that the genetic determination of growth rate has correlated effects on puberty.

Reproduction (2011) 141 381-389
\end{abstract}

\section{Introduction}

Understanding the genetic mechanism between growth rate and the onset of puberty is of significant biological and agricultural interest. Identification of quantitative trait loci (QTL) and their related genetic relationships is important in understanding the genetic factors controlling reproductive traits associated with sexual maturity, such as age and weight at puberty. Several studies across species have shown that the attainment of puberty (sexual maturity) is dependent on a number of factors such as age, minimum weight and body composition (Frisch 1994, Yannakopoulos et al. 1995, Eitan \& Soller 2001).

In humans, the attainment of a critical body weight of $48 \mathrm{~kg}$ and a fat percentage of $22 \%$ for the onset of puberty in girls was proposed in the early 1970 s (Frisch \& Revelle 1970). Recent interest in this issue has been reignited by the observed early puberty in girls associated with increasing levels of obesity (Kaplowitz 2008, Aksglaede et al. 2009). Similarly, agricultural species that have been intensely selected for early growth, such as broiler chickens, have also become heavier and higher in body fat content, with negative effects on their reproductive performance as adults (Hocking et al. 2002, Brewer \& Balen 2010). Early maturity has also been associated with reproductive problems such as abnormal ovarian hierarchies in chickens (Lacassag \& Jacquet 1965, Hocking et al. 1987, Hocking 2004), and understanding the genetic mechanisms influencing these conditions could shed light on reproductive dysfunction in other species (Onagbesan et al. 2009).

The existence of a threshold level of weight or fatness that is critical for menarche has been disputed (Garn et al. 1983). The hypothesis that puberty depends on a critical amount of body fat has been rejected repeatedly by experimentalists (Bronson 2001). The linkage between body fat and the reproductive axis in girls is thought to be the result of an evolutionary mechanism in mammals for ensuring that pregnancy will not occur unless there are adequate fat stores to sustain both the mother and the growing foetus (Kaplowitz 2008). According to Kaplowitz (2008), published evidence suggests that obesity may be causally related to earlier puberty in girls. Rodent and human studies suggest that leptin is the critical link between body fat and early puberty but the question of whether earlier puberty is 
the cause or the result of increased body fat has not been resolved (Kaplowitz 2008).

An alternative view based on chicken studies is that the fat deposition is a result of processes associated with steroidogenesis driven by the development of the ovary (Hocking \& Robertson 2000). Some authors have suggested that there is a minimum fat requirement and that body weight is not a limiting factor for achievement of sexual maturity (Robinson et al. 2001) whereas Soller et al. (1984) showed that a critical body fat content was not required for the attainment of puberty. While some data point to a possible minimum fat requirement to attain sexual maturity, a cautious approach is needed to identify the actual mechanisms involved (Chen et al. 2007) and that there is possible distortion due to effects of selection (Reddish et al. 2003).

The chicken (Gallus gallus domesticus) is a model organism used in genetic studies with implications for agriculture and biology (Griffin \& Goddard 1994, Burt 2007). The relative ease of using chickens to generate DNA-based genetic data and the similarities in the sexual maturity phenomena across species makes the chicken a relevant model to gain more understanding of the genetic relationship between growth rate and the onset of sexual maturity across species. Interactions of several loci have been reported to influence early growth in chickens, for example (Carlborg et al. 2003), but genetic mechanisms involved in the interplay of other factors impacted by early growth remain to be elucidated.

This study adopted a QTL approach to address four issues. First, to investigate the relationship between growth rate and sexual maturity by identifying the QTL for age at first egg (AFE) and weight at first egg (WFE) in the Roslin broiler-layer cross in which the White Leghorn layer was much later maturing than the male broiler line. Secondly, to identify the relative importance of age and body weight for the attainment of puberty in chickens. Thirdly, reproductive traits are known to exhibit high heterosis (Williams et al. 2002), which may be explained partly by epistasis, the non-additive interaction of genes with one another (Williams et al. 2002, Carlborg et al. 2004, Melchinger et al. 2007). For this reason, the effects of epistasis on AFE and WFE were investigated using recently developed software (Wei et al. 2009). Finally, we investigated the effect of adiposity on puberty by using abdominal fat weight $(A B F)$ as a covariate due to its high correlation with WFE and total body fat.

\section{Results}

\section{Broiler and layer phenotypes}

The mean AFE and WFE of the broiler male line and the White Leghorn layer line are presented in Table 1. At first egg, the broiler line was heavier (5.4 vs $1.5 \mathrm{~kg}$ ) and earlier maturing than the layer (130 vs 177 days).
Table 1 Means and s.D.s for age, abdominal fat and weight at the onset of lay in male line broiler and White Leghorn layer chicken females.

\begin{tabular}{|c|c|c|c|c|}
\hline \multirow[b]{2}{*}{ Trait } & \multicolumn{2}{|c|}{$\begin{array}{c}\text { Male line } \\
\text { broiler }(n=10)\end{array}$} & \multicolumn{2}{|c|}{$\begin{array}{l}\text { White Leghorn } \\
\text { layer }(n=12)\end{array}$} \\
\hline & Mean & S.D. & Mean & S.D. \\
\hline Weight at first egg, WFE (kg) & 5.4 & 0.6 & 1.5 & 0.1 \\
\hline Age at first egg, AFE (days) & 130 & 8 & 177 & 10 \\
\hline Abdominal fat, ABF (g) & 255 & 71 & 44 & 9 \\
\hline
\end{tabular}

\section{$F_{2}$ phenotypes}

Trait means, s.D.s, ranges and phenotypic correlations between the phenotypic traits in the $F_{2}$ population are given in Table 2. AFE for the $F_{2}$ population ranged from 99 to 226 days. The mean AFE for the broiler male line stock and $F_{2}$ were similar (130 and 134 days respectively) and lower than that of the White Leghorn layer line (177 days). The Pearson correlation between WFE and the natural logarithm of AFE minus 94 days (InAFE94) in the $F_{2}$ population was low (0.31; Table 2). The transformation of AFE was done to normalise residual errors.

\section{Location of QTL and genetic effects}

Without InAFE94 as a covariate, significant effects were detected on chromosomes 2, 4, 8, 27 and Z (Table 3) for WFE. Two peaks of significance were found on the $\mathrm{Z}$ chromosome and their confidence intervals $(\mathrm{Cl})$ barely overlap. This suggests that two QTL affecting WFE may be located in this chromosome. When including InABF as a covariate in the analysis of WFE, an additional QTL on chromosome 1 became significant but evidence was lost for the Z chromosome QTL. Including InAFE94 as a covariate for WFE detected a further three QTL on chromosomes 3, 13 and 28, with only one of the original Z chromosome QTL being significant. The mapped QTL varied widely in their effects explaining from 1.0 to $9.5 \%$ of trait variance in WFE, with half of the QTL

Table 2 Number of records $(N)$, means, S.D.s, range and phenotypic correlations for age, weight, natural logarithm of age-94 days and abdominal fat at the onset of lay in an $F_{2}$ broiler-layer chicken population.

\begin{tabular}{|c|c|c|c|c|c|c|c|}
\hline \multirow[b]{2}{*}{ Variable } & \multirow[b]{2}{*}{$N$} & \multirow[b]{2}{*}{ Mean } & \multirow[b]{2}{*}{ S.D. } & \multirow[b]{2}{*}{ Min } & \multirow[b]{2}{*}{ Max } & \multicolumn{2}{|c|}{ Correlation } \\
\hline & & & & & & AFE & WFE \\
\hline $\begin{array}{l}\text { Weight at first } \\
\text { egg, WFE (kg) }\end{array}$ & 912 & 2.9 & 0.4 & 1.4 & 42 & 0.32 & - \\
\hline $\begin{array}{c}\text { Age at first egg, } \\
\text { AFE (days) }\end{array}$ & 912 & 134.2 & 21.1 & 99 & 226.0 & - & 0.32 \\
\hline $\begin{array}{l}\ln (\text { AFE94) } \\
\ln (\text { days })\end{array}$ & 912 & 3.56 & 0.54 & 1.61 & 4.88 & - & 0.31 \\
\hline $\begin{array}{l}\text { Abdominal fat, } \\
\text { ABF (g) }\end{array}$ & 455 & 134.5 & 48.0 & 17.4 & 409.2 & 0.27 & 0.71 \\
\hline $\ln A B F, \ln (g)$ & 455 & 4.84 & 0.37 & 2.86 & 6.01 & 0.18 & 0.69 \\
\hline
\end{tabular}


Table 3 Chromosome, F ratio, quantitative trait loci (QTL) position, confidence interval, flanking markers, additive and dominance effects and proportion of phenotypic variation explained for weight at first egg (WFE) with and without adjustment for covariates in a broiler-layer $F_{2}$ chicken population.

\begin{tabular}{|c|c|c|c|c|c|c|c|}
\hline Chrom & $F_{\text {ratio }^{a}}$ & Position (cM) & $\mathrm{Cl}$ & Flanking markers & $\begin{array}{c}\text { Additive } \\
\text { effect (S.E.M.) }\end{array}$ & $\begin{array}{l}\text { Dominance } \\
\text { effect (S.E.M.) }\end{array}$ & VP $(\%)$ \\
\hline \multicolumn{8}{|c|}{ WFE (with no covariate) (g) } \\
\hline 2 & $10.29^{\dagger}$ & 326 & $246-422$ & ADL0114-MCW0056 & 85 (18.6) & $2(31.2)$ & 1.9 \\
\hline 4 & $36.40^{+}$ & 157 & $144-184$ & ADL0241-MCW0180 & $381(45.1)$ & $170(172.3)$ & 7.2 \\
\hline 8 & $10.10^{\dagger}$ & 60 & $0-74$ & MCW0100-ROS0075 & $110(25.0)$ & $38(48.2)$ & 1.9 \\
\hline 27 & $19.00^{\dagger}$ & 0 & 0 & ROS0071 & $107(17.3)$ & $2(25.1)$ & 3.7 \\
\hline Z & $9.23^{*}$ & 103 & $63-127$ & LEI0111-LEI0075 & $96(31.6)$ & - & 1.0 \\
\hline $\bar{Z}$ & $10.64^{+}$ & 0 & $0-65$ & ROS0072-ADLO201 & $82(25.0)$ & - & 1.0 \\
\hline Total & & & & & 861 & 212 & 16.7 \\
\hline \multicolumn{8}{|c|}{ WFE (InABF fitted as covariate) (g) } \\
\hline 1 & $11.25^{+}$ & 134 & $118-494$ & LEI0068-LEI146 & $89(18.2)$ & $12(27.7)$ & 4.1 \\
\hline 2 & $10.17^{*}$ & 325 & $246-340$ & ADL0114-MCW0056 & $82(17.9)$ & $52(31.1)$ & 4.1 \\
\hline 4 & $15.79^{+}$ & 175 & 147-195 & ADL0241-MCW0180 & $201(33.8)$ & $-39(93.1)$ & 6.3 \\
\hline 8 & $7.87^{\ddagger}$ & 23 & $0-63$ & ADL0179-MCW0095 & $71(18.5)$ & $-6(26.1)$ & 2.4 \\
\hline 27 & $23.30^{\dagger}$ & 0 & 0 & ROS0071 & $124(17.0)$ & $-6.8(26.0)$ & 9.5 \\
\hline Total & & & & & 567 & 21.2 & 26.4 \\
\hline \multicolumn{8}{|c|}{ WFE (InAFE94 fitted as covariate) (g) } \\
\hline 1 & $8.78^{*}$ & 141 & $90-501$ & LEI0068-LEI0146 & $64(16.5)$ & $42(24.3)$ & 1.5 \\
\hline 2 & $16.65^{+}$ & 307 & $285-333$ & ROS0074-ADL0114 & $95(17.2)$ & $-50(29.7)$ & 3.0 \\
\hline 3 & $7.42^{\ddagger}$ & 136 & $11-250$ & MCW0127-LEI0118 & $43.8(16.1)$ & $63(22.4)$ & 1.2 \\
\hline 4 & $45.05^{\dagger}$ & 155 & $144-172$ & ADL00241-MCW0180 & $401(41.8)$ & $-94(164.7)$ & 8.3 \\
\hline 8 & $9.93^{+}$ & 60 & $12-78$ & MCW0100-ROS0075 & $100(22.6)$ & 39 (43.4) & 1.7 \\
\hline 13 & $7.43^{+}$ & 54 & $26-68$ & MCW0340-ADL0225 & $101(27.3)$ & $-85(57.9)$ & 1.2 \\
\hline 27 & $31.82^{+}$ & 0 & 0 & ROS0071 & $125(15.5)$ & $8(22.6)$ & 5.8 \\
\hline 28 & $6.98^{\ddagger}$ & 1 & $0-39$ & ROS0095-ROS0085 & $-62(16.3)$ & $-1(22.7)$ & 1.1 \\
\hline Z & $14.65^{+}$ & 17 & $0-113$ & ROS0072-ADL0201 & $116(30.2)$ & - & 1.6 \\
\hline Total & & & & & 983.8 & -78 & 25.4 \\
\hline
\end{tabular}

Chrom, chromosome; $\mathrm{Cl}, 95 \%$ confidence interval; VP\%, percentage of phenotypic variation explained by the QTL; InABF, loge (abdominal fat weight); InAFE94, $\log _{\mathrm{e}}$ (age at first egg minus 94 days).

${ }^{a}$ Significant at $0.05(*)$ and $0.01(\dagger)$ levels experiment-wide, and (‡) suggestive.

explaining $2.4 \%$ or more of the trait variance. QTL on chromosomes 4 and 27 accounted for the highest proportion of phenotypic variation (8.3 and 5.8\% respectively) when including InAFE94 in the analysis. Without WFE as a covariate, only one significant QTL for InAFE94 was detected on chromosome 2 with suggestive QTL on chromosomes 1, 3, 13 and 15. With WFE as a covariate, the evidence for a QTL became significant in similar regions of chromosomes 1 and 13 . In addition, QTL were found on chromosomes 4, 27 and a different region of chromosome 3. There was also evidence for two QTL on both chromosomes 3 and 4 (Table 4). The QTL explained relatively small proportions of $1.0-3.1 \%$ of the phenotypic variation for InAFE94; only two of the QTL had effects explaining $2.0 \%$ or more of trait variation.

A QTL was detected for InAFE94 and for WFE in similar regions on chromosome 2 , indicating that the same QTL may influence both traits. With no covariate in the analysis, this was the only QTL found to affect both WFE and AFE. With the alternative trait as covariate in the analysis, however, there was extensive commonality with QTL significant for the two traits on chromosomes $1,2,3,4,13$ and 27 . The effects of including a covariate in the analysis will be considered in detail in the 'Discussion' section.
The additive effects for the WFE QTL were all positive, indicating that the increasing allele was from the broiler line (Table 3), except for the suggestive QTL on chromosome 28, which had a negative estimate. Dominance effects were not significant indicating that dominance was not an important mode of gene action for this trait. The largest (401 g) and the smallest (64 g) additive effects observed for significant WFE QTL were respectively on chromosomes 4 and 1 when InAFE94 was fitted as a covariate. The mapped QTL accounted for almost half of the difference in trait value between the two parental lines, and $25 \%$ of $F_{2}$ trait variance. Inclusion of InAFE94 as a covariate in the analysis for this trait increased the number of significant QTL and slightly increased the magnitude of the effects for each QTL. Fitting InABF as a covariate had less effect on the results.

The results for the additive and dominance effects for InAFE94 QTL are presented in Table 4. Here, too, the dominance effects were not significant. Similar to WFE, the additive gene action was also important for InAFE94. The QTL additive effects for InAFE94 were small and mainly negative. The mapped QTL accounted for $14 \%$ of $F_{2}$ trait variance, but only a small proportion of the difference between the two parental lines. There was no support for epistatic interactions between QTL for either trait. 
Table 4 Chromosome, F ratio, quantitative trait loci (QTL) position, confidence interval, flanking markers, additive and dominance effects and proportion of phenotypic variation explained for the natural logarithm transformed age at first egg (InAFE94) in a broiler-layer $F_{2}$ chicken population.

\begin{tabular}{|c|c|c|c|c|c|c|c|}
\hline Chr & $\boldsymbol{F}_{\text {ratio }}{ }^{\mathrm{a}}$ & Position (cM) & $\mathbf{C l}$ & Flanking markers & $\begin{array}{c}\text { Additive } \\
\text { effect } \pm \text { s.E.M. }\end{array}$ & $\begin{array}{r}\text { Dominance } \\
\text { effect } \pm \text { S.E.M. }\end{array}$ & VP $(\%)$ \\
\hline \multicolumn{8}{|c|}{ InAFE94 (with no covariate fitted), In(days) } \\
\hline 1 & $5.70^{\ddagger}$ & 164 & $0-380$ & LEI0146-ADL0319 & $-0.07(0.022)$ & $0.06(0.042)$ & 1.1 \\
\hline 2 & $8.43^{*}$ & 291 & $115-358$ & ROSO023-ADL0236 & $-0.06(0.017)$ & $0.04(0.025)$ & 1.7 \\
\hline 3 & $5.50^{\ddagger}$ & 24 & $16-185$ & MCW0083-HUJ0006 & $-0.07(0.021)$ & $0.01(0.035)$ & 1.0 \\
\hline 13 & $7.00^{\neq}$ & 0 & $0-44$ & MCW0340-ADL0225 & $-0.07(0.018)$ & $0.02(0.027)$ & 1.4 \\
\hline 15 & $5.47^{\ddagger}$ & 41 & $11-49$ & LEI0083-MCW0080 & $-0.08(0.025)$ & $0.02(0.052)$ & 1.5 \\
\hline Total & & & & & -0.35 & 0.15 & 6.7 \\
\hline \multicolumn{8}{|c|}{ InAFE94 (with WFE fitted as a covariate), In(days) } \\
\hline 1 & $9.0^{\dagger}$ & 153 & $30-386$ & LEI0146-ADL0319 & $-0.08(0.019)$ & $0.01(0.032)$ & 1.7 \\
\hline 2 & $15.4^{\dagger}$ & 291 & $229-298$ & ROS0023-ADL0236 & $-0.08(0.015)$ & $0.05(0.023)$ & 3.1 \\
\hline 3 & $8.2^{*}$ & 139 & $5-230$ & MCW0127-LEI0118 & $-0.06(0.017)$ & $-0.05(0.024)$ & 1.5 \\
\hline 3 & $7.7^{\ddagger}$ & 23 & $9-250$ & MCW0083-HUJ0006 & $-0.07(0.019)$ & $-0.03(0.031)$ & 1.4 \\
\hline 4 & $8.1^{*}$ & 195 & $65-195$ & ADL0241-MCW0180 & $-0.08(0.021)$ & $-0.06(0.037)$ & 1.5 \\
\hline 4 & $6.7^{\ddagger}$ & 3 & $0-194$ & ADL0317-MCW0295 & $-0.07(0.018)$ & $0.01(0.028)$ & 1.2 \\
\hline 13 & $8.6^{*}$ & 20 & $0-46$ & MCW0340-ADL0225 & $-0.11(0.026)$ & $-0.01(0.057)$ & 1.6 \\
\hline 27 & $10.1^{\dagger}$ & 0 & - & ROS0071 & $-0.06(0.016)$ & $-0.04(0.023)$ & 2.0 \\
\hline Total & & & & & -0.61 & -0.12 & 14 \\
\hline
\end{tabular}

Chr, chromosome; $\mathrm{Cl}, 95 \%$ confidence interval; VP\%, percentage of phenotypic variation explained by the QTL; InAFE94, loge (age at first egg minus 94 days); WFE, weight at first egg.

${ }^{a}$ Significant at $0.05(*)$ and $0.01(\dagger)$ levels experiment-wide, and $(\neq)$ suggestive.

\section{Discussion}

\section{Effect of including a covariate in the QTL analysis}

Including a genetically controlled and phenotypically correlated trait as a covariate in the analysis will affect the evidence for a QTL at a specific location, depending on the direction and magnitude of QTL effects on the two traits (Goddard et al. 2001, Neuschl et al. 2007, Chiu et al. 2010). If the QTL affects the trait, but not the covariate, inclusion of the covariate will increase the evidence for the QTL. This may have happened for the QTL for WFE on chromosome 27, when InAFE was fitted as covariate. If the QTL affects the covariate but not the trait, inclusion of the covariate will identify a QTL for the covariate rather than a QTL for the trait under investigation. The QTL on chromosomes 4 and 27 originally detected for WFE became significant for InAFE94 when WFE was included as a covariate, suggesting that these QTL affected WFE rather than InAFE94. If the QTL affects both the trait and the covariate (i.e. a pleiotropic QTL), the ability to detect it will depend on the QTL and the phenotypic correlations (i.e. the evidence may be lost or enhanced). In this study, the traits in the $F_{2}$ were positively correlated phenotypically (i.e. individuals with late AFE tended to have high WFE, since these birds had more time to gain weight before first egg). QTL operating in the same direction in both traits, consistent with the phenotypic correlation, will generally lose evidence when one of the traits is fitted as a covariate in the analysis of the other. Apparently, this is what happened to the QTL on chromosomes 4, 8 and $Z$ when InABF was fitted as a covariate to WFE (Table 3). The original breed difference, however, implies that birds with later AFE have low WFE and vice versa. This will tend to enhance the evidence for such a pleiotropic QTL and increase the effect estimates when fitting one of the traits as a covariate in the analysis of the other. The QTL identified for both WFE and InAFE94 on chromosome 2 could be such a case, as significance for both traits increased when the alternative trait was used as a covariate. The QTL on chromosomes 1 and 13 detected for InAFE94 became significant when WFE was included as a covariate, and were also identified for WFE when InAFE94 was included as a covariate. These could be additional examples of pleiotropic QTL, with the QTL affecting both WFE and InAFE94. Finally, the QTL on chromosome 3 in interval MCW0127-LEI0118 may be another example as it was detected for both traits but only in the presence of the other as a covariate. In each of these instances, as an alternative to pleiotropy, the co-location of QTL affecting each of the two traits could be due to separate tightly clustered loci that individually influence a single trait (Almasy et al. 1997). A better way to detect pleiotropic QTL would be to analyse the traits simultaneously (Knott \& Haley 2000).

\section{Importance of the identified QTL}

The sum of the additive effects for significant WFE QTL was $0.86 \mathrm{~kg}$ accounting for $1.7 \mathrm{~kg}$ additive effects difference between the lines. This represents $44 \%$ of the live weight difference $(3.9 \mathrm{~kg})$ between the lines at the onset of lay (Table 1). For all of these QTL, the allele increasing WFE was inherited from the broiler line, which is consistent with the breed difference (Table 1). 
The sum of the additive effects for InAFE94 (adjusted for WFE) was $\sim 12$ days. This represents an additive effect difference of 24 days or about half the phenotypic difference between the lines (Table 1). In comparison to this analysis, when the covariate was not fitted the sum of the additive effects was only 3.4 days, explaining $<15 \%$ of the line difference. This is consistent with the conclusion that QTL for weight rather that age explain far more of the observed difference in age at onset of puberty between the lines.

Additive effects for InAFE94 were generally negative (Table 4) indicating that the broiler line was earlier maturing than the layer genotype (consistent with the breed differences, Table 1) and is consistent with the expectation that fast growing (heavy) birds tend to reach sexual maturity earlier. However, it should be noted that the layer line was unusually late maturing (Table 1), possibly due to the lack of photostimulation in this experiment. A constant photoperiod was adopted to avoid confounding differences in maturity with the timing of photostimulation.

\section{QTL affecting early growth rate affect WFE}

An earlier study on broiler offspring of the same parents as the present data (Sewalem et al. 2002) reported significant QTL for live weight at earlier ages (3-9 weeks of age) than in this study on chromosomes $1,7,13$ and Z (for 3 weeks of age), chromosomes 1, 2, 4, 7, 8, 13 (for 6 weeks of age) and on chromosomes 1, 2, 4, 8, 13 and 27 (for 9 weeks of age). In that study, covariates were not fitted in the analysis. Even though the earlier study used much younger ages (3-9 weeks) than in our study (19 weeks of age), the QTL detected for live weight (in the earlier study) and for WFE (without a covariate) in our study were at similar positions across the implicated linkage groups.

Similar results were obtained when comparing our results on WFE with those of other studies on early growth rate. The highly significant QTL for body weight on chromosome 4 detected in this study confirm findings from several studies that have reported large effect body weight QTL on this chromosome (Schreiweis et al. 2006). Zhou et al. (2006) reported significant QTL for body weight at 8 weeks of age in a broiler-White Leghorn cross on chromosomes 1, 2, 4, 7, 9 and 18. Body weight QTL (at 7 weeks of age) were reported on chromosomes 1, 2 and 13 from a broiler population (Atzmon et al. 2006). Ruy et al. (2005) reported four suggestive QTL on chromosome 3 and three suggestive QTL on chromosome 5 for WFE from a layer-broiler cross. Thus, the growth QTL reported in other studies were also in similar chromosome positions to the ones observed in our study and this suggests that sexual maturity QTL are generally not distinct from those for growth.

In contrast to our results, Carlborg et al. (2003) observed a pronounced role of epistatic effects on growth prior to 46 days of age in a red jungle fowl-White Leghorn cross and reported significant QTL for body weight in the 1-200 days age bracket on chromosomes 1, 2, 3, 4, 7, 8, 11, 12, 13, 14, 27 and E27W24. The important contribution of epistasis to early growth (before 6 weeks of age) was also observed in a White Leghorn layer and broiler sire line cross population from the same parents as the present flock (Carlborg et al. 2004).

The WFE QTL on chromosome 27 appears worthy of special attention. When InABF was used as a covariate, this QTL explained almost $10 \%$ of the phenotypic variance in WFE. The QTL is located in a region that contains several growth-related genes (e.g. chicken growth hormone $(G H)$; Lei et al. 2007). The G+1705A in Intron 3 of $\mathrm{GH}$ could have a direct effect on chicken growth via an influence on $\mathrm{GH}$ gene expression (Nie et al. 2005).

There are specific QTL (on chromosomes 8 and 13) associated with age and weight at sexual maturity, which are not found when analysing weight at younger ages. However, the magnitude of their additive effects for InAFE94 is relatively small, suggesting that there is limited opportunity to genetically manipulate sexual maturity independently of commercial broiler growth traits.

Schreiweis et al. (2006) reported a suggestive AFE QTL on chromosome 3, which is similar to the location of a QTL in this study. AFE QTL have also been reported on chromosome 4 (Schreiweis et al. 2006). However, a QTL for AFE reported on chromosome $Z$ by Tuiskula-Haavisto et al. (2002) and Sasaki et al. (2004) was not detected in this study.

\section{Abdominal fat, body weight and puberty}

The high correlation (0.71) between ABF and WFE (Table 2) suggests that these traits are controlled by similar factors. Circulating lipids increase at the onset of lay for deposition into the developing yolky follicles (Jaccoby et al. 1995). The accumulation of body fat is likely to be important for this reason, as it is a source of circulating lipid as well as de novo synthesis in the liver. Therefore, the use of InABF to model QTL affecting WFE may identify regions of the genome, which are associated with lean tissue mass, at the onset of lay. The fact that the majority of the QTL are not affected by fitting body fat as a covariate suggests that the amount of fat does not explain the onset of sexual maturity in poultry (Soller et al. 1984) except in the case of QTL on chromosome 1.

In general, the results are consistent with the concept that achieving a minimum body weight is permissive for the attainment of sexual maturity (Brody et al. 1984, Eitan \& Soller 2001). This is interesting because the estimated WFE QTL effects at these locations are genetically determined and are not the 
result of dietary manipulation. Therefore, this may be one of the clearest demonstrations that genetic determination of growth rate results in correlated effects on puberty. The possibility that the converse is true can be eliminated because the effects of the growth QTL take place before the age of puberty is reached. Clear evidence of genetic correlations between growth rate and puberty are not numerous: studies in female pigs suggest that there is a negative phenotypic correlation between growth and puberty (Hutchens et al. 1981) and in humans it was estimated that $57 \%$ of the additive genetic effects for the age of menarche and body mass index are common (Kaprio et al. 1995). The genetic and physiological determinates of sexual maturity underlying the QTL identified in this study remain to be elucidated through a combination of fine mapping and identification of candidate genes for subsequent validation.

In conclusion, the QTL for WFE and InAFE94 detected in this study generally acted additively and the broiler alleles were associated with heavier body weights and earlier ages at the onset of lay. The indication that the loci for growth and puberty are common provides a clear demonstration of the genetic basis for the phenotypic correlation between growth and puberty and that body weight is an important determinant for the attainment of sexual maturity.

\section{Materials and Methods}

\section{Parent lines}

One-day-old female chicks were obtained from the Ross 308 male line broiler (Aviagen, Newbridge, UK) and a White Leghorn egg laying line maintained at the Roslin Institute. The chicks were brooded and reared under conventional husbandry practices in floor pens. At 12 weeks of age, 12 birds from each line were randomly allocated to individual cages to record phenotypic data on the age and weight at the onset of lay. However, for the broilers, only ten birds that survived were used.

\section{Animals and genotyping}

The $F_{2}$ population was created by crossing two males and two females from the broiler male line with two females and two males from the White Leghorn line to produce an $F_{1}$ generation (Sewalem et al. 2002). Eight males and 32 females of the $F_{1}$ generation were selected and mated in a balanced mating scheme to produce over $2000 \mathrm{~F}_{2}$ birds (one $\mathrm{F}_{1}$ female died and was replaced making a total of 33 full sib families). The female birds were reared in floor pens and moved to individual cages that measured $40 \mathrm{~cm}$ wide $\times 45 \mathrm{~cm}$ deep $\times 80 \mathrm{~cm}$ high at 12 weeks of age. The birds were fed ad libitum on a conventional poultry diet. The birds were exposed to a constant photoperiod of $14 \mathrm{~h}$ per day from hatch to the end of the experiment. WFE and AFE were recorded at the onset of lay, which was defined as the day of first recorded oviposition. In a subset of the birds (about half of the hatches), the birds were killed and the weight of abdominal fat was recorded. AFE was transformed to natural logarithms of (AFE - 94 days) to normalise residual errors. The 94 days was chosen as the lowest AFE in the unedited data. The QTL effects on the original scale were calculated from the back-transformed means of the three genotype classes. The additive effects were obtained from the average of the backtransformed means of the two homozygotes.

Blood samples were obtained after caging for extracting DNA by standard methods (Sewalem et al. 2002). Genotyping was conducted using 106 microsatellite markers covering 25 autosomal linkage groups and the $Z$ sex chromosome (Table 5) on the $8 F_{0}$ grandparents, $41 F_{1}$ and $912 F_{2}$ offspring with data on age and WFE. All pedigree, marker genotypes and recorded traits were stored in the resSpecies database (Law \& Archibald 2000). The 2005 consensus genetic linkage map (ArkDB, 2007) was used to add new markers to a linkage map based on the same population used in the analysis (Navarro et al. 2005). The total map length was $2479 \mathrm{cM}$ (Table 5).

\section{QTL analysis}

The interval mapping method (Haley et al. 1994) for QTL detection was conducted using a newly developed module for analysis of epistasis in GridQTL (Seaton et al. 2006, Wei et al. 2009). The programme initially conducts the standard processes of QTL searching, testing, permutation and bootstrapping for a single QTL $F_{2}$ analysis. Genome scans were conducted iteratively using forward selection of significant QTL for each trait (Carlborg et al. 2004). Analyses were performed at $1 \mathrm{cM}$

Table 5 The number of microsatellite markers, first and last marker and map length on each linkage chromosome in the quantitative trait loci analysis of the chicken broiler-layer cross.

\begin{tabular}{lcllc}
\hline Chromosome & $\begin{array}{c}\text { Number } \\
\text { of } \text { markers }\end{array}$ & $\begin{array}{c}\text { First } \\
\text { marker }\end{array}$ & $\begin{array}{c}\text { Last } \\
\text { marker }\end{array}$ & $\begin{array}{c}\text { Map } \\
\text { length (cM) }\end{array}$ \\
\hline 1 & 17 & ROSO008 & MCW0107 & 548 \\
2 & 13 & LEI0163 & MCW0157 & 473 \\
3 & 15 & MCW0169 & MCW0037 & 286 \\
4 & 4 & ADL0317 & MCW0180 & 195 \\
5 & 5 & ROS0013 & ADL0298 & 119 \\
6 & 4 & ADL0323 & ADL0142 & 113 \\
7 & 3 & LEI0064 & ADL0180 & 109 \\
8 & 9 & ROS0021 & ROSO075 & 92 \\
9 & 4 & ROS0078 & MCW0134 & 132 \\
10 & 1 & ADL0209.2 & ADL0209 & - \\
11 & 5 & LEI0110 & ROS00112 & 71 \\
12 & 2 & ADL0240 & ADL0044 & 34 \\
13 & 2 & MCW0340 & ADL0225 & 68 \\
14 & 1 & MCW0123 & MCW0123 & - \\
15 & 2 & LEI0083 & MCW0080 & 49 \\
16 & 1 & LEI0258 & LEI0258 & - \\
17 & 1 & ADL0199 & ADL0199 & - \\
18 & 2 & ROS0022 & ROSO027 & 24 \\
19 & 1 & MCW0094 & MCW0094 & - \\
22 & 1 & ROS0073 & ROSO073 & - \\
23 & 1 & MCW0249 & MCW0249 & - \\
26 & 2 & ADL0285 & LEI0074 & - \\
27 & 1 & ROS0071 & ROSO071 & - \\
28 & 3 & ROS0095 & ADL0299 & 39 \\
Z & 6 & ROS0072 & LEI0075 & 127 \\
Total & 106 & & & 2479 \\
\hline & & & & \\
\hline
\end{tabular}


intervals. Exhaustive QTL searches with an updated model were implemented by fitting the significant QTL as co-factors (Jansen 1994, Zeng 1994) until no additional significant QTL were detected.

Epistatic QTL were mapped simultaneously by extending the method for a single QTL search using a linear model with marginal effects for a pair of QTL and their four possible pairwise interactions in 1 cM genome scans (Wei et al. 2009). A significant outcome in the overall test of the marginal effects and all two-way interactions between the additive and dominance effects at two loci and of this test compared to the two-locus model with no inter-locus interactions is indicative of epistasis. The method detects epistatic pairs of QTL by using two complementary search approaches. In the first stage, the algorithm automates a genome scan to identify interactions between pre-identified single QTL with all the other genomic positions. In the second approach, a twodimensional genome scan involving all combinations of two positions in the genome is conducted to search for epistatic interactions regardless of the locations of the pre-identified marginal effect QTL.

\section{Determination of significance thresholds}

In single QTL detection, significance thresholds were determined by conducting 5000 permutations (Churchill \& Doerge 1994), and 1000 bootstraps were used to generate $95 \%$ Cl (Lander \& Botstein 1989, Visscher et al. 1996). A QTL was considered as being significant if it had an $F$ value greater than the $P \leq 0.05$ experiment-wide threshold value and highly significant if the $F$ value exceeded the $P \leq 0.01$ threshold (Kruglyak \& Lander 1995). Alternatively, the QTL was considered to be suggestive if it had an $F$ value exceeding the $P \leq 0.05$ chromosome-wide threshold. All significant and suggestive QTL were used in the first approach for detection of epistatic QTL pairs.

Significance testing for epistatic pairs in both approaches used $F$ ratio tests for model comparisons in a nested test framework. Permutations based on 1000 replications were used to determine genome-wide thresholds. In the first stage, exhaustive genome scans were performed on permuted data to derive thresholds for each pre-identified marginal effect QTL. The DIRECT algorithm (Ljungberg et al. 2004) was used to perform fast two-dimensional genome scans in permutations to derive genome-wide thresholds for the second stage (Wei et al. 2009).

\section{Models}

In a preliminary analysis, different models with additive, dominance and parent-of-origin genetic effects with family and pen as fixed effects were analysed (hatch was confounded with pen). There was no evidence for parent-of-origin effects (detected as a difference in effect between the alternative heterozygous genotypes that differ in which allele has been inherited from each parent), and a simple additive-dominance model was adopted for subsequent analyses. Additive genetic effects were defined as half the difference between the broiler and layer homozygotes and dominance effects as the difference between the heterozygote and the mean of the two homozygotes (Falconer \& Mackay 1996). A positive additive effect indicates that the QTL allele originating from the broiler line increased the trait value relative to that from the layer line. The $\mathbf{Z}$ chromosome was analysed with an additive genetic effects model.

For each trait, models with and without a covariate were fitted. Covariates were included in the model of analysis to detect differences in the assessed trait at a fixed level of the covariate trait (Kerje et al. 2003, Park et al. 2006). A regression analysis on InAFE94 and WFE showed that InAFE94 explained $29 \%$ of the variation in WFE where pen and family were included as fixed effects. Conversely, fitting the same effects, WFE explained a moderately high proportion of the variation $(64 \%)$ in InAFE94. In the QTL analysis for WFE, InAFE94 was added in the model as a covariate. Additionally, for the subset of the individuals with $A B F$ recorded, another model was run for WFE with InABF as a covariate. Similarly, WFE was fitted as a covariate in the model for InAFE94.

The percentage of the $F_{2}$ phenotypic variance explained by the QTL was calculated as percentage variance= $((\mathrm{RRMS}-\mathrm{FRMS}) / \mathrm{RRMS}) \times 100$ (Zhou et al. 2006), where RRMS is the residual mean square from the reduced model in which all the effects including background QTL effects are fitted but the QTL is omitted. The FRMS is the residual mean square from the model in which all the effects and QTL are fitted.

\section{Declaration of interest}

The authors declare that there is no conflict of interest that could be perceived as prejudicing the impartiality of the research reported.

\section{Funding}

The authors gratefully acknowledge the funding for B K Podisi from the Botswana Government. The experiments were funded by grants from the EU, Defra and BBSRC. The Roslin Institute is supported by the Biotechnology and Biological Sciences Research Council.

\section{Acknowledgements}

S A Knott acknowledges support from RCUK. The male line broiler chicks were kindly provided by Aviagen Ltd, Newbridge, Midlothian, EH25 8SZ. B K Podisi also acknowledges support from the Biosciences Knowledge Transfer Network. The authors thank an anonymous referee for the helpful suggestions on improving the original version of the manuscript.

\section{References}

Aksglaede L, Juul A, Olsen LW \& Sørensen TIA 2009 Age at puberty and the emerging obesity epidemic. PLoS ONE 4 e8450. (doi:10.1371/journal. pone.0008450)

Almasy L, Dyer TD \& Blangero J 1997 Bivariate quantitative trait linkage analysis: pleiotropy versus co-incident linkages. Genetic Epidemiology 14 953-958. (doi:10.1002/(SICI)1098-2272(1997)14:6<953::AID-GEPI65 $>3.0 . \mathrm{CO} ; 2-\mathrm{K})$ 
Atzmon G, Ronin YI, Korol A, Yonash N, Cheng H \& Hillel J 2006 QTLs associated with growth traits and abdominal fat weight and their interactions with gender and hatch in commercial meat-type chickens. Animal Genetics 37 352-358. (doi:10.1111/j.1365-2052.2006.01487.x)

Brewer CJ \& Balen AH 2010 The adverse effects of obesity on conception and implantation. Reproduction 140 347-364. (doi:10.1530/REP-09-0568)

Brody TB, Siegel PB \& Cherry JA 1984 Age, body weight and body composition requirements for the onset of sexual maturity of dwarf and normal chickens. British Poultry Science 25 245-252. (doi:10.1080/ 00071668408454863)

Bronson FH 2001 Puberty in female mice is not associated with increases in either body fat or leptin. Endocrinology 142 4758-4761. (doi:10.1210/ en.142.11.4758)

Burt DW 2007 Emergence of the chicken as a model organism: implications for agriculture and biology. Poultry Science 86 1460-1471.

Carlborg O, Kerje S, Schutz K, Jacobsson L, Jensen P \& Andersson L 2003 A global search reveals epistatic interaction between QTL for early growth in the chicken. Genome Research 13 413-421. (doi:10.1101/gr.528003)

Carlborg O, Hocking PM, Burt DW \& Haley CS 2004 Simultaneous mapping of epistatic QTL in chickens reveals clusters of QTL pairs with similar genetic effects on growth. Genetical Research 83 197-209. (doi:10.1017/S0016672304006779)

Chen H, Huang RL, Zhang HX, Di KQ, Pan D \& Hou YG 2007 Effects of photoperiod on ovarian morphology and carcass traits at sexual maturity in pullets. Poultry Science $\mathbf{8 6}$ 917-920.

Chiu Y-F, Chiou J-M, Liang K-Y \& Lee C-Y 2010 Incorporation of covariates in simultaneous localization of two linked loci using affected relative pairs. BMC Genetics 11 67. (doi:10.1186/1471-2156-11-67)

Churchill GA \& Doerge RW 1994 Empirical threshold values for quantitative trait mapping. Genetics 138 963-971.

Eitan Y \& Soller M 2001 Effect of photoperiod and quantitative feed restriction in a broiler strain on onset of lay in females and onset of semen production in males: a genetic hypothesis. Poultry Science $\mathbf{8 0}$ 1397-1405.

Falconer DS \& Mackay TFC 1996 Introduction to Quantitative Genetics, 4th edn. Harlow: Longman Group Ltd.

Frisch RE 1994 The right weight: body fat, menarche and fertility. Proceedings of the Nutrition Society 53 113-129. (doi:10.1079/ PNS19940015)

Frisch RE \& Revelle R 1970 Height and weight at menarche and a hypothesis of critical body weights and adolescent events. Science 169 397-399. (doi:10.1126/science.169.3943.397)

Garn SM, LaVelle M \& Pilkington J 1983 Comparisons of fatness in premenarcheal and postmenarcheal girls of the same age. Journal of Pediatrics 103 328-331. (doi:10.1016/S0022-3476(83)80379-5)

Goddard KAB, Witte JS, Suarez BK, Catalona WJ \& Olson JM 2001 Modelfree linkage analysis with covariates confirms linkage of prostate cancer to chromosomes 1 and 4. American Journal of Human Genetics 68 1197-1206. (doi:10.1086/320103)

Griffin HD \& Goddard C 1994 Rapidly growing broiler (meat-type) chickens. Their origin and use for comparative studies of the regulation of growth. International Journal of Biochemistry 26 19-28. (doi:10.1016/ 0020-711X(94)90190-2)

Haley CS, Knott SA \& Elsen JM 1994 Mapping quantitative trait loci in crosses between outbred lines using least squares. Genetics 136 1195-1207.

Hocking P 2004 Roles of body weight and feed intake in ovarian follicular dynamics in broiler breeders at the onset of lay and after a forced molt. Poultry Science 83 2044-2050.

Hocking PM \& Robertson GW 2000 Ovarian follicular dynamics in selected and control (relaxed selection) male- and female-lines of broiler breeders fed ad libitum or on restricted allocations of food. British Poultry Science 41 229-234. (doi:10.1080/713654904)

Hocking PM, Gilbert AB, Walker M \& Waddington D 1987 Ovarian follicular structure of white leghorns fed ad libitum and dwarf and normal broiler breeders fed ad libitum or restricted until point of lay. British Poultry Science 28 493-506. (doi:10.1080/00071668708416983)

Hocking PM, Bernard R \& Robertson GW 2002 Effects of low dietary protein and different allocations of food during rearing and restricted feeding after peak rate of lay on egg production, fertility and hatchability in female broiler breeders. British Poultry Science 43 94-103. (doi:10. 1080/00071660120109908)
Hutchens LK, Hintz RL \& Johnson RK 1981 Genetic and phenotypic relationships between pubertal and growth characteristics of gilts. Journal of Animal Science 53 946-951.

Jaccoby S, Arnon E, Snapir N \& Robinzon B 1995 Effects of estradiol and tamoxifen on feeding, fattiness, and some endocrine criteria in hypothalamic obese hens. Pharmacology, Biochemistry, and Behavior 50 55-63. (doi:10.1016/0091-3057(94)00251-D)

Jansen RC 1994 Controlling the type I and type II errors in mapping quantitative trait loci. Genetics 138 871-881.

Kaplowitz PB 2008 Link between body fat and the timing of puberty. Pediatrics 121 S208-S217. (doi:10.1542/peds.2007-1813F)

Kaprio J, Rimpela A, Winter T, Viken RJ, Rimpela M \& Rose RJ 1995 Common genetic influences on $\mathrm{BMI}$ and age at menarche. Human Biology 67 739-753.

Kerje S, Carlborg Ö, Jacobsson L, Schütz K, Hartmann C, Jensen P \& Andersson L 2003 The twofold difference in adult size between the red junglefowl and White Leghorn chickens is largely explained by a limited number of QTLs. Animal Genetics 34 264-274. (doi:10.1046/j.13652052.2003.01000.x)

Knott SA \& Haley CS 2000 Multitrait least squares quantitative trait loci detection. Genetics 156 899-911.

Kruglyak L \& Lander ES 1995 A nonparametric approach for mapping quantitative trait loci. Genetics 139 1421-1428.

Lacassag L \& Jacquet JP 1965 Maturite sexuelle et apparition doeufs a double jaune et sans coquille. Role du regime lumineux et du niveau alimentaire (Sexual maturity and appearance of double-yolked and shellless eggs. Role of light treatment and nutritional level). Annales de Zootechnie 14 169-179. (doi:10.1051/animres:19650204)

Lander ES \& Botstein D 1989 Mapping mendelian factors underlying quantitative traits using RFLP linkage maps. Genetics 121 185-199.

Law AS \& Archibald AL 2000 Farm animal genome databases. Briefings in Bioinformatics 1 151-160. (doi:10.1093/bib/1.2.151)

Lei M, Luo C, Peng X, Fang M, Nie Q, Zhang D, Yang G \& Zhang X 2007 Polymorphism of growth-correlated genes associated with fatness and muscle fiber traits in chickens. Poultry Science $\mathbf{8 6} 835-842$.

Ljungberg K, Holmgren S \& Carlborg O 2004 Simultaneous search for multiple QTL using the global optimization algorithm DIRECT. Bioinformatics 20 1887-1895. (doi:10.1093/bioinformatics/bth175)

Melchinger AE, Utz HF, Piepho H-P, Zeng Z-B \& Schon CC 2007 The role of epistasis in the manifestation of heterosis: a systems-oriented approach. Genetics 177 1815-1825. (doi:10.1534/genetics.107.077537)

Navarro P, Visscher PM, Knott SA, Burt DW, Hocking PM \& Haley CS 2005 Mapping of quantitative trait loci affecting organ weights and blood variables in a broiler layer cross. British Poultry Science 46 430-442. (doi:10.1080/00071660500158055)

Neuschl C, Brockmann GA \& Knott SA 2007 Multiple-trait QTL mapping for body and organ weights in a cross between NMRI8 and DBA/2 mice. Genetical Research 89 47-59. (doi:10.1017/S001667230700852X)

Nie Q, Sun B, Zhang D, Luo C, Ishag NA, Lei M, Yang G \& Zhang X 2005 High diversity of the chicken growth hormone gene and effects on growth and carcass traits. Journal of Heredity 96 698-703. (doi:10.1093/jhered/ esi114)

Onagbesan O, Bruggeman V \& Decuypere E 2009 Intra-ovarian growth factors regulating ovarian function in avian species: a review. Animal Reproduction Science 111 121-140. (doi:10.1016/j.anireprosci.2008. 09.017)

Park H-B, Jacobsson L, Wahlberg P, Siegel PB \& Andersson L 2006 QTL analysis of body composition and metabolic traits in an intercross between chicken lines divergently selected for growth. Physiological Genomics 25 216-223. (doi:10.1152/physiolgenomics.00113.2005)

Reddish JM, Nestor KE \& Lilburn MS 2003 Effect of selection for growth on onset of sexual maturity in randombred and growth-selected lines of Japanese quail. Poultry Science 82 187-191.

Robinson FE, Renema RA, Oosterhoff HH, Zuidhof MJ \& Wilson JL 2001 Carcass traits, ovarian morphology and egg laying characteristics in early versus late maturing strains of commercial egg-type hens. Poultry Science $8037-46$.

Ruy DC, Nones K, Baron EE, Ledur MC, Rodrigues de Melo CM, Ambo M, Campos RDLR \& Coutinho LL 2005 Strategic marker selection to detect quantitative trait loci in chicken. Scientia Agricola 62 111-116. (doi:10. 1590/S0103-90162005000200003) 
Sasaki O, Odawara S, Takahashi H, Nirasawa K, Oyamada Y, Yamamoto R, Ishii K, Nagamine Y, Takeda H, Kobayashi E et al. 2004 Genetic mapping of quantitative trait loci affecting body weight, egg character and egg production in $\mathrm{F}_{2}$ intercross chickens. Animal Genetics 35 188-194. (doi:10.1111/j.1365-2052.2004.01133.x)

Schreiweis MA, Hester PY, Settar P \& Moody DE 2006 Identification of quantitative trait loci associated with egg quality, egg production, and body weight in an $\mathrm{F}_{2}$ resource population of chickens. Animal Genetics 37 106-112. (doi:10.1111/j.1365-2052.2005.01394.x)

Seaton GHJ, Grunchec JA, White I, Allen J, De Koning DJ, Wei W, Berry D, Haley C \& Knott S 2006 GridQTL: a grid portal for QTL mapping of compute intensive datasets. In Proceedings of the 8th World Congress on Genetics Applied to Livestock Production, Belo Horizonte, MG, Brazil.

Sewalem A, Morrice DM, Law A, Windsor D, Haley CS, Ikeobi CO, Burt DW \& Hocking PM 2002 Mapping of quantitative trait loci for body weight at three, six, and nine weeks of age in a broiler layer cross. Poultry Science 81 1775-1781.

Soller M, Brody T, Eitan Y, Agursky T \& Wexler C 1984 Minimum weight for the onset of sexual maturity in female chickens: heritability and phenotypic correlations with early growth rate. Poultry Science 63 2103-2113.

Tuiskula-Haavisto M, Honkatukia M, Vilkki J, de Koning DJ, Schulman NF \& Maki-Tanila A 2002 Mapping of quantitative trait loci affecting quality and production traits in egg layers. Poultry Science 81 919-927.
Visscher PM, Thompson R \& Haley CS 1996 Confidence intervals in QTL mapping by bootstrapping. Genetics 143 1013-1020.

Wei WH, Knott S, Haley CS \& de Koning DJ 2009 Controlling false positives in the mapping of epistatic QTL. Heredity 104 401-409. (doi:10.1038/ hdy.2009.129)

Williams SM, Price SE \& Siegel PB 2002 Heterosis of growth and reproductive traits in fowl. Poultry Science 81 1109-1112.

Yannakopoulos AL, Christaki E \& Florou-Paneri P 1995 Effect of age and carcase composition on the onset of sexual maturity in quail under normal feeding regimens. British Poultry Science 36 771-777. (doi:10. 1080/00071669508417821)

Zeng ZB 1994 Precision mapping of quantitative trait loci. Genetics 136 1457-1468.

Zhou H, Deeb N, Evock-Clover CM, Ashwell CM \& Lamont SJ 2006 Genome-wide linkage analysis to identify chromosomal regions affecting phenotypic traits in the chicken. I. Growth and average daily gain. Poultry Science 85 1700-1711.

Received 14 June 2010

First decision 12 August 2010

Revised manuscript received 14 December 2010

Accepted 22 December 2010 